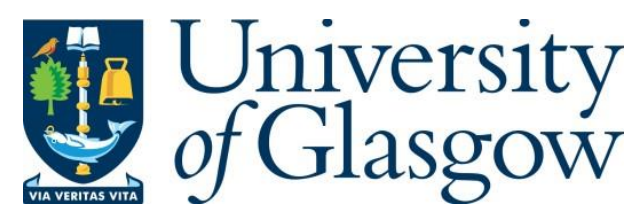

Ur-Rehman, M., Malik, N. A., Yang, X., Abbasi, Q. H., Zhang, Z. and Zhao, N. (2017) A low profile antenna for millimeter-wave body-centric applications. IEEE Transactions on Antennas and Propagation, (doi:10.1109/TAP.2017.2700897).

There may be differences between this version and the published version. You are advised to consult the publisher's version if you wish to cite from it.

http://eprints.gla.ac.uk/141167/

Deposited on: 20 July 2017

Enlighten - Research publications by members of the University of Glasgow http://eprints.gla.ac.uk 


\title{
A Low Profile Antenna for Millimetre-Wave Body-Centric Applications
}

\author{
Masood Ur-Rehman, Senior Member, IEEE, Nabeel Ahmed Malik, Xiaodong Yang, Member, IEEE, Qammer \\ Hussain Abbasi, Senior Member, IEEE, Zhiya Zhang and Nan Zhao
}

\begin{abstract}
Millimetre-Wave frequencies are a front runner contender for the next generation body-centric wireless communications. In this paper, design of a very low profile antenna is presented for body-centric applications operating in the millimetre-wave frequency band centred at $60 \mathrm{GHz}$. The antenna has an overall size of $14 \times 10.5 \times 1.15 \mathrm{~mm}^{3}$ and is printed on a flexible printed circuit board. The performance of the antenna is evaluated in off-body, on-body and body-to-body communication scenarios using a realistic numerical phantom and verified through measurements. The antenna has a bandwidth of $9.8 \mathrm{GHz}$ and offers a gain of $10.6 \mathrm{dBi}$ in off-body (free space) configuration while $12.1 \mathrm{dBi}$ in on-body configuration. It also acheives an efficiency of $74 \%$ in off-body and $63 \%$ in on-body scenario. The small and flexible structure of the antenna along with excellent impedance matching, broad bandwidth, high gain and good efficiency makes it a suitable candidate to attain simultaneous data transmission/reception at millimetre-wave frequencies for the $5 \mathrm{G}$ body-centric applications.
\end{abstract}

Index Terms-Millimetre-Wave, 5G, Body-centric applications, Remote health monitoring.

\section{INTRODUCTION}

Body-centric networks (BCNs) are one of the most attractive venues for the next generation wireless technologies due to a huge range of applications. Body-centric devices are offering wide variety of services. Though personal health care is the dominant field, its applications cover navigation and tracking, detection and localisation, sports and fitness, infotainment and gaming, augmented reality and smart watches [1]-[4]. They are also expected to play a very important role in 5G and Internet-of-Things (IoT) [1]. The popularity and applicability of the body-centric networks had resulted in a massive annual device shipment of 20 million units in 2015 and is estimated to rise to 187.2 million units by 2020 [5], [6].

The millimetre-wave (mm-Wave) band at $60 \mathrm{GHz}(57-$ $64 \mathrm{GHz}$ ) has recently received much interest for the BCNs due to high demand of increased network capacity and data rates. No requirement of licensing and possible adoption for $5 \mathrm{G}$ technologies further adds to its popularity [1], [7]. Low interference and confidentiality due to high atmospheric

M. Ur Rehman and N. A. Malik are with the School of Computer Science \& Technology, University of Bedfordshire, Luton LU1 3JU, UK, e-mail: masood.urrehman@beds.ac.uk.

X. Yang, N. Zhao and Z. Zhang are with the School of Electronic Engineering, Xidian University, Xi'an, Shaanxi, 710071, China, email: xdyang@xidian.edu.cn.

Q. A. Abbasi is with the School of Engineering, University of Glasgow, Glasgow G12 8QQ, UK.

Corresponding authors: M. Ur-Rehman and X. Yang. attenuation is another source of attraction for $60-\mathrm{GHz} \mathrm{BCNs}$ [1].

Antennas are a key element in the design and successful deployment of the BCNs. The BCN antenna design is a very challenging task due to multiple requirements to ensure mobility, reliable link and robustness. The BCN antennas are required to have low profile, small size, light weight and should be flexible to offer conformity with the human body shape [8]. Low power consumption is another restriction that needs to be followed [9]. Broad bandwidth and high gain is also required for the mm-Wave operation to fulfil high data rate demands [7]. Additionally, the impact of human user's presence on such antennas must be characterised as the human body is an inherent part of BCN applications. The antennas operating in the vicinity of the human body are subject to electromagnetic distortions due to absorptions in the lossy human body tissues and reflections/scattering from the body surface [2]. Efficient performance of BCN systems therefore, requires a detailed evaluation of the interaction between the human body and wearable antennas. Moreover, current tele-health systems and future $5 \mathrm{G} / \mathrm{IoT}$ application scenarios necessitate inter-connectivity between body-worn sensors, body-worn access points and remote processing units [1].

A huge amount of effort has been put by researchers worldwide to study the performance of the antennas in on/off body scenarios. It is now well established that the proximity of the human tissues brings high level of losses over the communication spectrum. It affects the antenna performance by detuning frequency and distorting radiation pattern [2], [10]. Although lower frequency ranges offer a wide variety of antenna solutions coping with these performance hurdles employing slot patches [11], embroidered fabrics [12], flexible substrates [13], [14] and substrate integrated waveguides [15] to name few, these challenges remain for the mm-Wave frequency band and need further exploration [16], [17].

Design of mm-Wave antennas have attracted interest of many researchers but few of these studies consider wearable scenarios. Wu et al. have presented a substrate integrated waveguide Yagi-Uda antenna in [18] that makes use of via rows as directors. Two periodic rows of metallic vias are also employed to form the sidewalls of the waveguide. An end-fire Yagi-Uda antenna array consisting of four single Yagi antennas each having a driven dipole, 18 directors, and a reflector has been presented in [19]. This antenna requires a microstrip-to-waveguide transition 


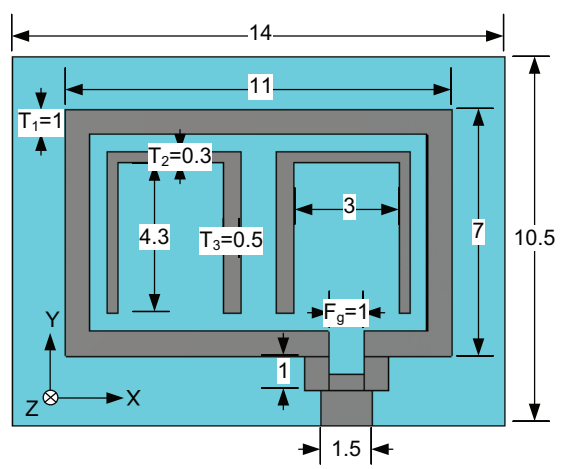

(a) Front view

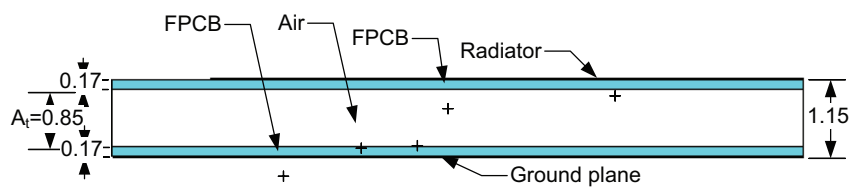

(b) Side view

Fig. 1. Geometry and dimensions of the proposed millimetre-wave antenna (all units are in $\mathrm{mm}$ ).

at the feed point. A Yagi-Uda antenna printed on a fabric substrate having a permittivity of 1.5 is discussed by Chahat et al. [20]. A disc-like antenna having an electromagnetic coupling between a circular disc and the feeding pin is presented in [21]. This antenna is using substrate integrated horn for the feeding. A planar end-fire substrate integrated waveguide horn antenna having $6.1 \mathrm{GHz}$ bandwidth has been designed by Razafimahatratra et al. [22]. A fourpatch $2 \times 2$ array antenna fed through a microstrip feed has been proposed in [23]. Lu et al. have used three-stage ladder-shaped directors to enhance the directivity by 2.4$3.1 \mathrm{~dB}$ and bandwidth by $30 \%$ of a four-arm quasi-Yagi antenna [24]. A horizontally aligned H-shaped microstrip patch antenna fed by a microstrip line for $60 \mathrm{GHz}$ operation is discussed in [25] by Rabbani et al. This antenna accomplishes a bandwidth of $4.92 \mathrm{GHz}$ and gain of 10.1 $\mathrm{dBi}$. Liao et al. have proposed a planar aperture antenna on low-temperature cofired ceramic (LTCC) consisting of a complex geometry with an open cavity, cross-shaped strip, meshed ground and probe pads [26]. The antenna is fed using a feed network based on two differential striplines connecting the probe pads with two differential ports. The antenna generates dual-polarisation in $60 \mathrm{GHz}$ band.

These antennas employ either complex geometries, use fabrics or require special fabrication technologies. It limits their applicability due to cost and complexity. Moreover, only few of them consider the antenna performance in wearable scenarios. Therefore, a new design of a flexible patch antenna for $60 \mathrm{GHz}$ BCN operation is presented in this study. The antenna employs a simple and flexible slotted-patch type structure that covers V-band frequencies from $55 \mathrm{GHz}$ to $64.8 \mathrm{GHz}$. The performance of this antenna in off-body, on-body and body-to-body communication scenarios is investigated through numerical analysis. The simulated results are verified through measurements.
Following the introduction, this paper is organised in four sections. Section II discusses the antenna design and presents a detailed parametric study to understand the role of different structural parameters in its operation. Section III evaluates the antenna performance in off-body (free space) configuration through simulations and measurements. In section IV, operation of the proposed antenna in wearable conditions considering various on-body, on/off-body and body-to-body scenarios is analysed both numerically and experimentally. This section also provides a comparison between the proposed work and previously published related studies. Conclusions are drawn in Section $\mathrm{V}$.

\section{ANTENNA DESIGN AND INNOVATION}

\section{A. Concept and Topology}

Body-mounted devices often require low profile antennas to adhere with strict form factor. Simple geometry is also a preferred choice to reduce the complexity and associated cost. A patch-type structure is considered helpful in obtaining these goals. Moreover, it also minimises the backward radiations towards the underlying human subject. The inherent separation between the radiator and the human body due to the presence of underlying substrate and ground plane also helps to minimise the impedance mismatch and maintain efficiency to certain extent. Therefore, a patch-like geometry is employed for the proposed antenna.

The antenna consists of two layers of flexible printed circuit board (FPCB) which helps to maintain the conformity and flexibility pertinent for the BCN devices. The FPCB have a relative permittivity of 2.7 and $\tan \sigma=0.005$. Thickness of the FPCB is $0.15 \mathrm{~mm}$. The antenna is fed through a microstrip feed line.

The overall size of the antenna is $14 \times 10.5 \times 1.15 \mathrm{~mm}^{3}$. The radiating element is combination of a rectangular loop and two U-shaped patches fed through a short microstrip feed line. For the centre frequency of $60 \mathrm{GHz}$, the optimised lengths and widths of the radiating elements, rectangular loop (RL) and U-shaped patches (UL), adhere to the following design principles:

$$
\begin{aligned}
& R L_{\text {width }}=1.4 \times \lambda_{60} \\
& R L_{\text {length }}=2.2 \times \lambda_{60}
\end{aligned}
$$

and,

$$
\begin{array}{r}
U P_{\text {width }}=R L_{\text {width }} / 2 \\
U P_{\text {length }}=R L_{\text {length }} / 2.4
\end{array}
$$

The proposed antenna is modelled numerically and simulated using CST Microwave Studio ${ }^{\circledR}$ that provides Finite Integration Technique (FIT) based solution of the Maxwell's equations [27]. The structural dimensions of the modelled antenna are shown in Fig. 1.

The electromagnetic coupling between the loop and the $\mathrm{U}$-shaped patches provides excitation to them. The loop is 


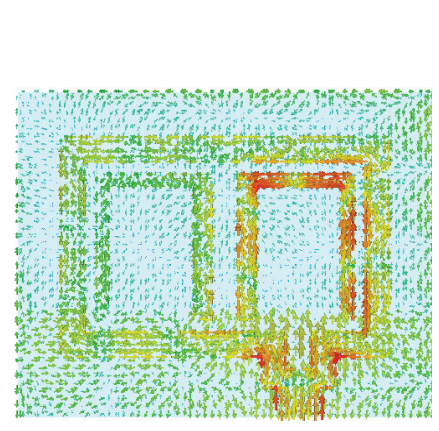

(a) $58 \mathrm{GHz}$

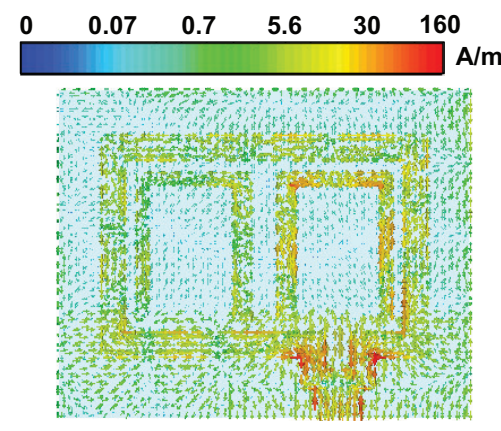

(b) $60 \mathrm{GHz}$

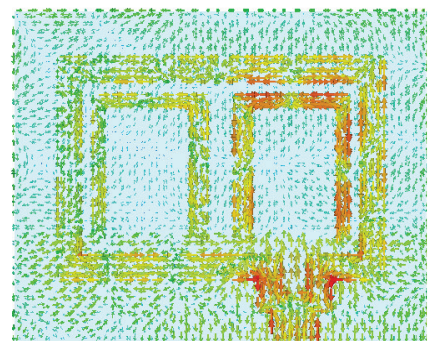

(c) $62 \mathrm{GHz}$

Fig. 2. Surface current distribution on the proposed antenna at $58 \mathrm{GHz}, 60 \mathrm{GHz}$ and $62 \mathrm{GHz}$.

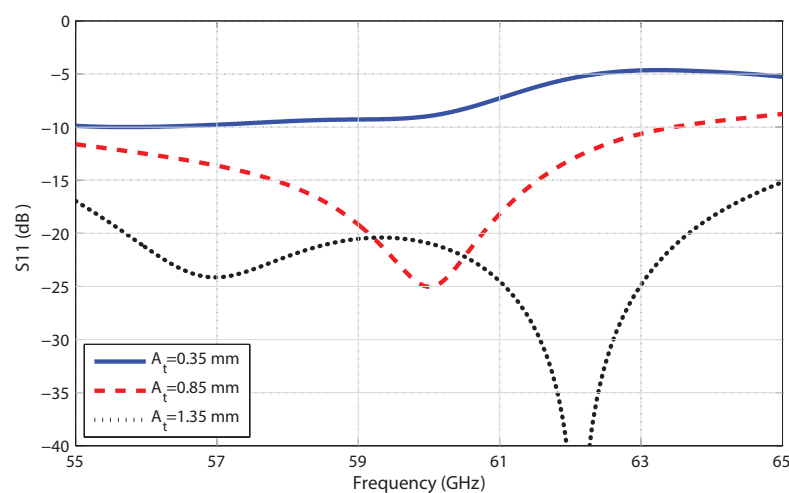

Fig. 3. Effects of thickness of the air substrate on the performance of the proposed antenna.

directly fed through a $50 \Omega$ microstrip line and provides feed balancing as evident from surface current distribution given in Fig. 2. The gap between the loop and the Ushaped patches is optimised to attain good impedance matching in $60 \mathrm{GHz}$ band. A standing wave pattern can also be observed from the current distribution on the loop and patches. To further enhance the performance of the antenna in terms of bandwidth and efficiency and minimise the detuning effects of the human body, an air substrate (air gap) is used between the top and bottom layers of the FPCB [14]. Though this arrangement results in a slightly less rigid structure, facilitation of body-conformity and increased performance in on-body scenarios (observed in Section IV) make this arrangement a good trade-off.

\section{B. Parametric Study}

Optimal antenna performance depends on an optimised configuration of various structural elements necessary for good impedance matching and radiation characteristics. This section investigates the effects of three key elements namely thickness of the air substrate, length of the feed gap and thickness of the rectangular loop on the performance of the proposed antenna to enhance the understanding of the antenna operating principle. The performance with the optimised values of these parameters is taken as a reference.

1) Thickness of the Air Substrate $\left(A_{t}\right)$ : Thickness of the air substrate $\left(A_{t}\right)$ between the two FPCB layers is one of the

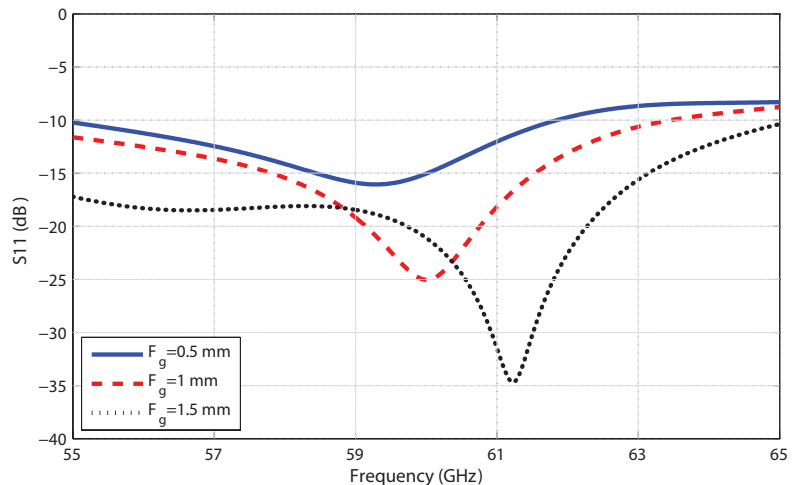

Fig. 4. Effects of length of the feed gap on the performance of the proposed antenna.

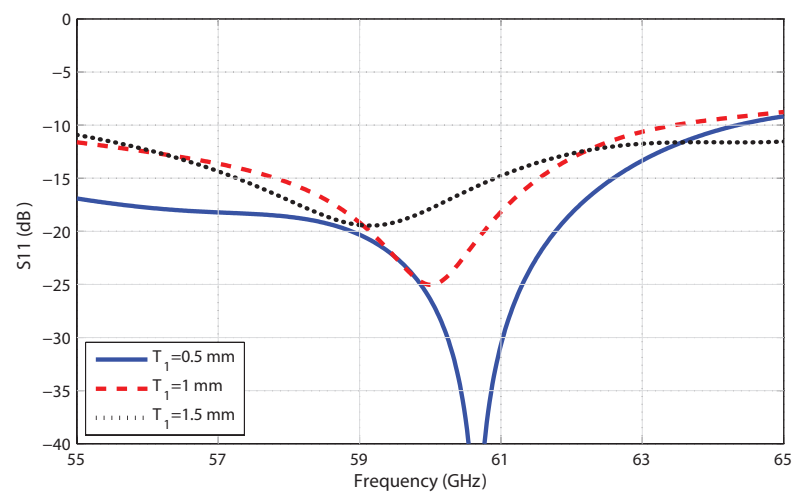

Fig. 5. Effects of thickness of the rectangular loop on the performance of the proposed antenna.

key elements in the proposed antenna design. Impact of this parameter on the impedance matching and bandwidth in terms of reflection coefficient $\left(S_{11}\right)$ is presented in Fig. 3. It can be observed that a thinner air substrate changes the impedance matching hugely making the antenna lose its -10 $\mathrm{dB}$ bandwidth completely at the required frequency band. A higher gap on the other hand, improves the matching and bandwidth. In comparison to the optimised $A_{t}=0.85 \mathrm{~mm}$, the antenna gain is reduced from $9.3 \mathrm{dBi}$ to $8.3 \mathrm{dBi}$ and 8.7 $\mathrm{dBi}$ while the efficiency is decreased to $64 \%$ and $66 \%$ from $69 \%$ for $A_{t}=0.35 \mathrm{~mm}$ and $A_{t}=1.35 \mathrm{~mm}$, respectively. 


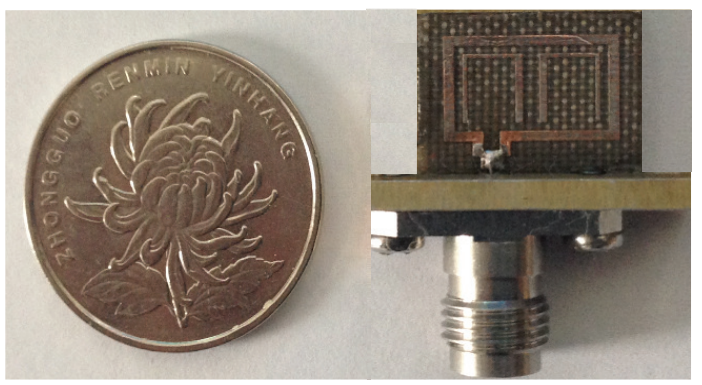

Fig. 6. Fabricated prototype of the proposed antenna fed by a V-connector.

2) Length of Feed Gap $\left(F_{g}\right)$ : Length of the feed gap $\left(F_{g}\right)$ also plays an important role in the antenna performance. Impact of varying values of this parameter is compared with the optimal value of $F_{g}=1 \mathrm{~mm}$ on the antenna working in terms of $S_{11}$ in Fig. 4. It is noted that a change in the feed gap length not only changes the bandwidth by shifting the resonance frequency but also varies the impedance matching. A lower gap degrades the matching and shifts the resonance towards the lower band losing almost half of the bandwidth at the upper end of the operational band. On contrary, an increased feed gap length improves the matching and enhances the bandwidth with resonance shifted to the higher frequency end. This parameter also affects the gain and efficiency of the antenna. The antenna exhibits a lowered gain of $8.7 \mathrm{dBi}$ and $9.0 \mathrm{dBi}$ for $F_{g}=0.5$ $\mathrm{mm}$ and $F_{g}=1.5 \mathrm{~mm}$, respectively. The efficiency reduces to $65 \%$ for $F_{g}=0.5 \mathrm{~mm}$ and increases to $89 \%$ for $F_{g}=1.5 \mathrm{~mm}$.

3) Thickness of the Rectangular Loop $\left(T_{1}\right)$ : The reflection coefficient response illustrated in Fig. 5 depicts that the thickness of the rectangular loop $\left(T_{1}\right)$ has an opposite impact on the antenna matching to that observed for the feed gap length. A lower value of $T_{1}$ improves the matching and shifts the resonance upwards while a thicker rectangular loop lessens the matching and shifts the resonance to a lower frequency. The $-10 \mathrm{~dB}$ bandwidth in the $60-\mathrm{GHz} \mathrm{mm}-$ Wave band remains intact in both cases. The gain of the antenna is noted to be $8.5 \mathrm{dBi}$ for $T_{1}=0.5 \mathrm{~mm}$ and $9.1 \mathrm{dBi}$ for $T_{1}=1.5 \mathrm{~mm}$. The efficiency becomes $68 \%$ and $85 \%$ for the two loop thicknesses, respectively.

\section{Antenna PERFormance in OfF-Body SCEnARIOS}

The impedance and radiation characteristics of the proposed mm-Wave antenna are studied in off-body (free space) configuration throughout the range of the operating frequencies in terms of reflection coefficient response, radiation patterns, peak gain and radiation efficiency. A prototype is fabricated and tested to verify the proposed antenna design. The fabricated antenna is shown in Fig. 6. A $\mathrm{V}$-connector is used to feed the prototype. The simulated results are then verified through experimental measurements in an anechoic chamber using Anritsu's MS4647B Vector Network Analyser (VNA).

Fig. 7 illustrates the reflection coefficient response of the proposed antenna. It can be observed from these results that the antenna exhibits a good impedance matching in

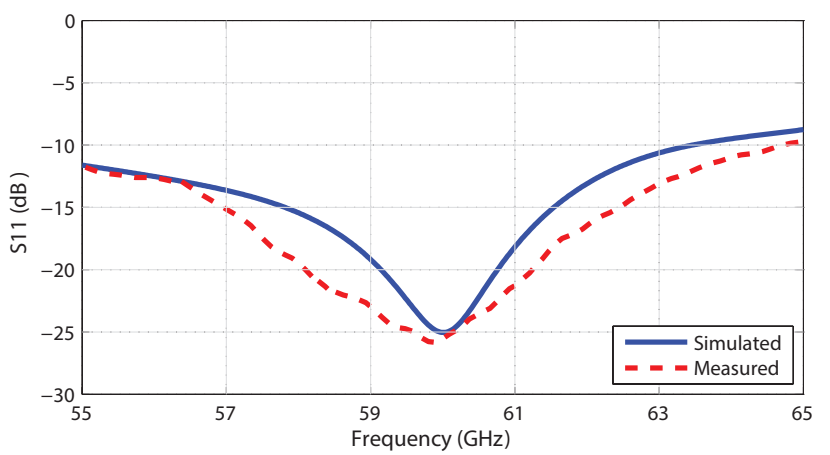

Fig. 7. Comparison of simulated and measured reflection coefficient response of the proposed antenna.

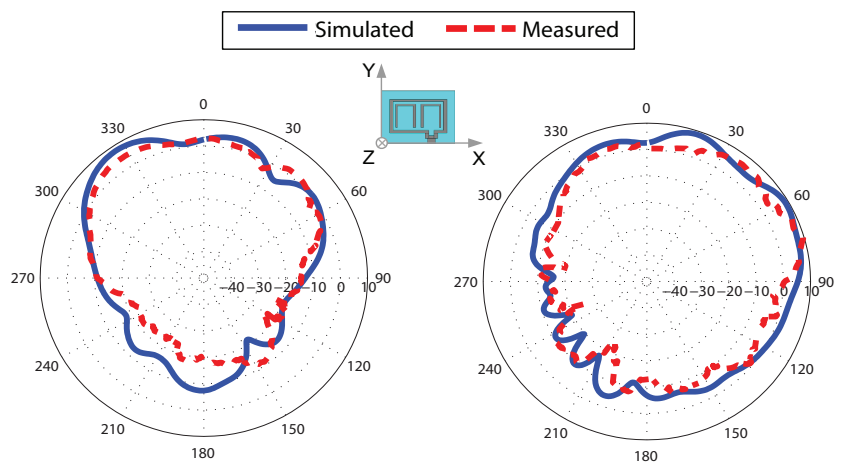

(i) XZ plane

(ii) YZ plane

(a) $f=58 G H z$

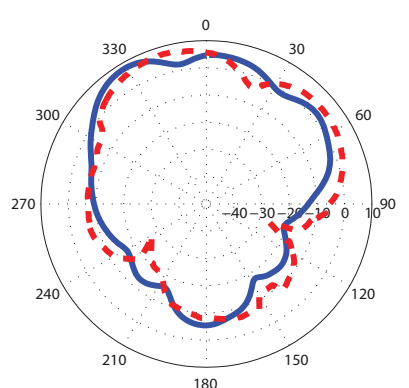

(i) XZ plane

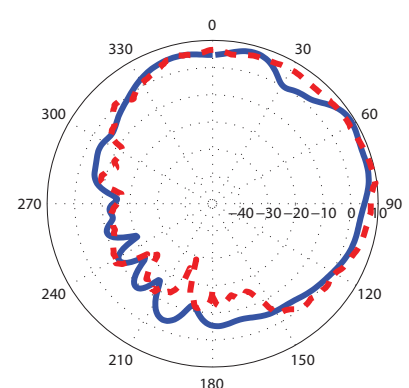

(ii) YZ plane

(b) $f=60 G H z$

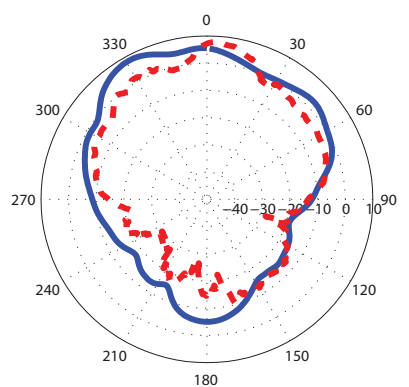

(i) $\mathrm{XZ}$ plane

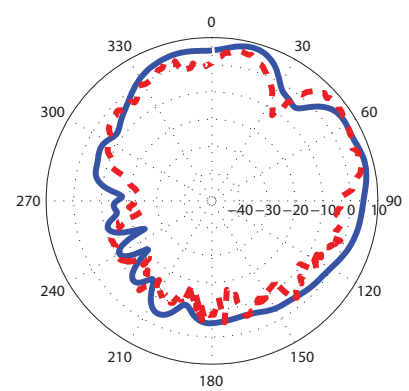

(ii) YZ plane (c) $f=62 G H z$

Fig. 8. Simulated and measured radiation patterns of proposed mm-Wave antenna in $\mathrm{XZ}$ and $\mathrm{YZ}$ planes at $58 \mathrm{GHz}, 60 \mathrm{GHz}$ and $62 \mathrm{GHz}$. 


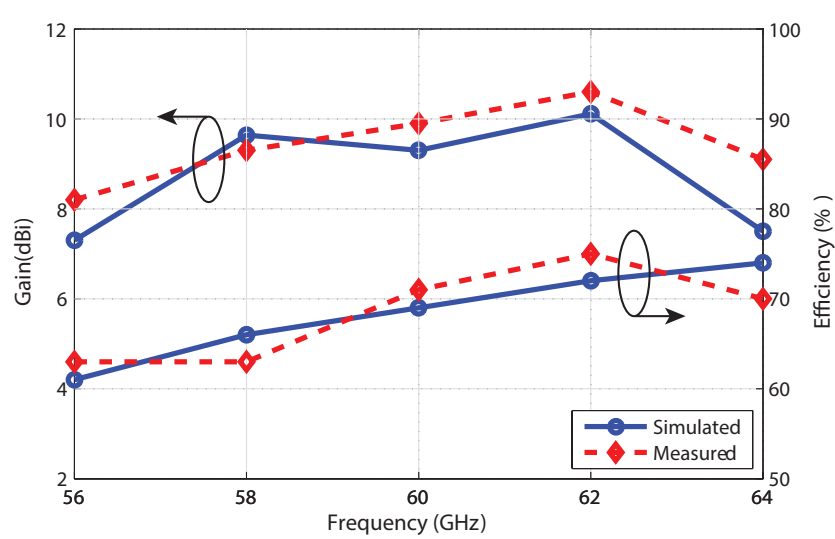

Fig. 9. Comparison of simulated and measured gain and efficiency of the proposed antenna.

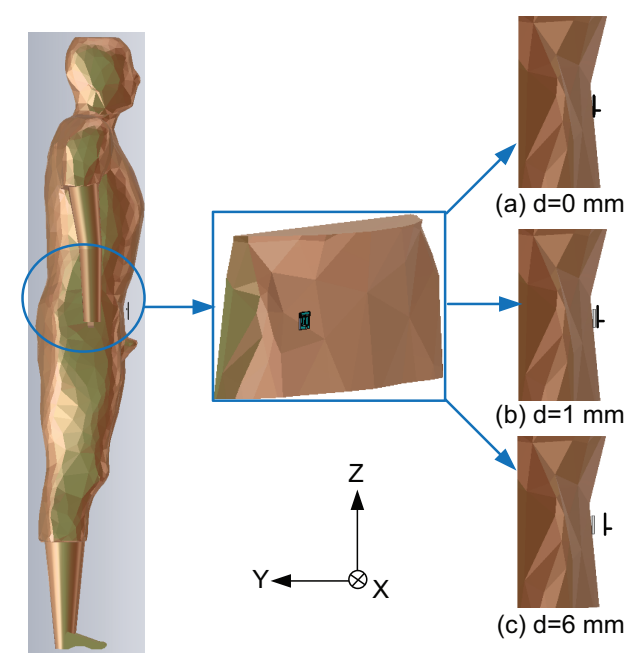

Fig. 10. Structure of realistic skin-equivalent human phantom taken out of a high-resolution human body model.

the $60 \mathrm{GHz}$ band. It provides a wide bandwidth covering frequencies from $55 \mathrm{GHz}$ to $63.4 \mathrm{GHz}$ in simulation while $55 \mathrm{GHz}$ to $64.8 \mathrm{GHz}$ in measurement. A good agreement between simulation and measurement is observed. The discrepancies are mainly attributed to fabrication imperfections and spurious radiations from coaxial cable and scattering on the V-connector.

A comparison of measured and simulated radiation patterns in XZ plane (azimuth) and YZ plane (elevation) in the range of frequencies of interest $(58 \mathrm{GHz}, 60 \mathrm{GHz}$ and $62 \mathrm{GHz}$ ) is shown in Fig. 8. Overall, the antenna exhibits good radiation coverage throughout the $60 \mathrm{GHz} \mathrm{mm}$-Wave frequency band. The radiation pattern is nearly omnidirectional in the YZ plane and provides coverage of the whole upper hemisphere in both the planes. It also covers almost all angles in the lower hemisphere in YZ plane but slightly distorted in $\mathrm{XZ}$ plane due to the presence of the Vconnector. The radiation pattern undergoes slight distortion at higher frequencies in both planes as expected. A good agreement between the simulation and measurement is again observed.

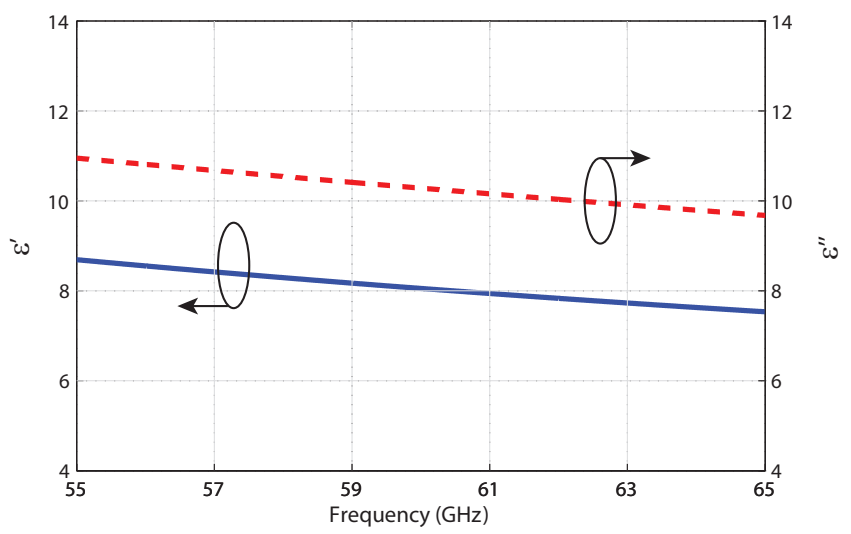

Fig. 11. Complex permittivity of dry skin in $55 \mathrm{GHz}-65 \mathrm{GHz}$ band.

Fig. 9 presents the comparison of simulated and measured peak gain and radiation efficiency of the proposed antenna throughout the frequencies of interest. The two results are in good agreement with a maximum difference of $1.6 \mathrm{dBi}$ in the gain and $4 \%$ in efficiency. The proposed antenna exhibits good performance in the $60 \mathrm{GHz}$ band achieving a maximum gain of $10.1 \mathrm{dBi}$ at $62 \mathrm{GHz}$ in simulation and $10.6 \mathrm{dBi}$ in measurement. The antenna gain is observed to be minimum $(7.3 \mathrm{dBi}$ in simulation and $8.2 \mathrm{dBi}$ in measurement) at $56 \mathrm{GHz}$. The antenna has a simulated efficiency of $66 \%, 69 \%$ and $71 \%$ at $58 \mathrm{GHz}, 60$ $\mathrm{GHz}$ and $62 \mathrm{GHz}$, respectively. This is in good agreement with the measured values of $61 \%, 71 \%$ and $74 \%$ at the three frequencies, respectively.

\section{Antenna Performance in Wearable Scenarios}

Human body presence distorts the antenna performance. It is therefore, pertinent that the BCN antennas should be tested in realistic body-worn scenarios. This section presents a detailed analysis and discussion on the antenna working in on-body, on/off-body and body-to-body configurations to establish its usability for interconnected body sensors and IoT applications.

\section{A. Numerical Modelling of the Skin Phantom}

The electromagnetic absorptions by the human body at $60 \mathrm{GHz}$ mainly takes place in the skin tissues due to a penetration depth of around $0.5 \mathrm{~mm}$ [1]. A single layer homogeneous torso phantom with electric properties of dry skin is therefore, employed to study the on-body antenna performance. The skin-equivalent phantom of the torso has been taken out of a high resolution whole-body model and thus, employs a realistic body shape. The overall dimensions of the phantom are $288 \times 100 \times 40 \mathrm{~mm}^{3}$ as shown in Fig. 10.

The overall number of cell volumes (voxels) in the computational domain and subsequently the computation and time requirements are reduced by using an adaptive meshing scheme in the CST Microwave Studio ${ }^{\circledR}$. The Perfectly Matched Layer (PML) absorbing boundary conditions are 


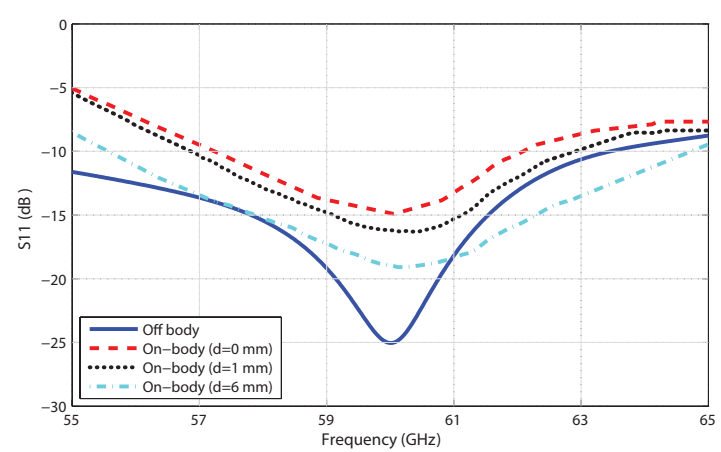

(a) Simulation

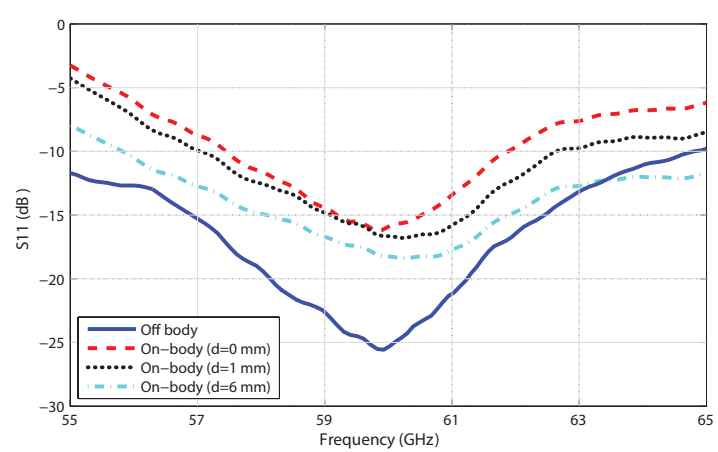

(b) Measurement

Fig. 12. Comparison of simulated and measured reflection coefficient response of the proposed antenna in three on-body configurations with off-body performance.

used [27]. It resulted in a maximum resolution of $2 \mathrm{~mm}$ near the boundaries of the computational domain.

The dielectric properties of the skin are well characterised up to $110 \mathrm{GHz}$ based on the extrapolation of data obtained through measurements up to $20 \mathrm{GHz}$ [28], [29]. Debye model with a single relaxation time is considered to exhibit good accuracy for modelling the permittivity data in $55 \mathrm{GHz}$ to $65 \mathrm{GHz}$ frequency range [30]:

$$
\varepsilon^{*}=\varepsilon_{o}\left(\varepsilon^{\prime}-j \varepsilon^{\prime \prime}\right)=\varepsilon_{o}\left(\varepsilon_{\infty}+\frac{\varepsilon_{s}-\varepsilon_{\infty}}{1+j \omega \tau}\right)
$$

where $\varepsilon_{o}$, is the free space permittivity $\left(8.85 \times 10^{-12} \mathrm{~F} / \mathrm{m}\right)$, $\varepsilon_{s}$ represents the static permittivity, $\varepsilon_{\infty}$ is the optical permittivity, $\omega$ depicts the angular frequency and $\tau$ is the relaxation time. The optimised values for the best fit in $55 \mathrm{GHz}$ to $65 \mathrm{GHz}$ range are: $\varepsilon_{s}=34.8, \varepsilon_{\infty}=4.1$ and $\tau=6.9 \times 10^{-12}$ [31]. The modelled permittivity values are given in Fig. 11.

\section{B. On-body Antenna Performance}

The performance of the antenna is evaluated in typical body-worn scenarios by placing it on top of the skin equivalent phantom. Three separations between the phantom and the antenna are considered including zero gap $(d=0 \mathrm{~mm})$, a gap of $1 \mathrm{~mm}(d=1 \mathrm{~mm})$ and a gap of $6 \mathrm{~mm}(d=6 \mathrm{~mm})$. First two configurations replicate antenna positioned directly onbody while third scenario provides a more realistic scenario having a clearance for the external casing of the $\mathrm{BCN}$ device (Fig. 10). Simulated results are confirmed through measurements in an anechoic chamber using physical phantom (a dielectric block having the electric properties of the dry skin given in Fig. 11).

Comparison of the reflection coefficient response and radiation patterns at the centre frequency of $60 \mathrm{GHz}$ between the three on-body scenarios and off-body operation (free space) is depicted in Figs. 12 and 13. A good agreement between the simulated and measured results can be observed from the presented results.

The results show that the human body effects on the antenna impedance matching are more significant for direct

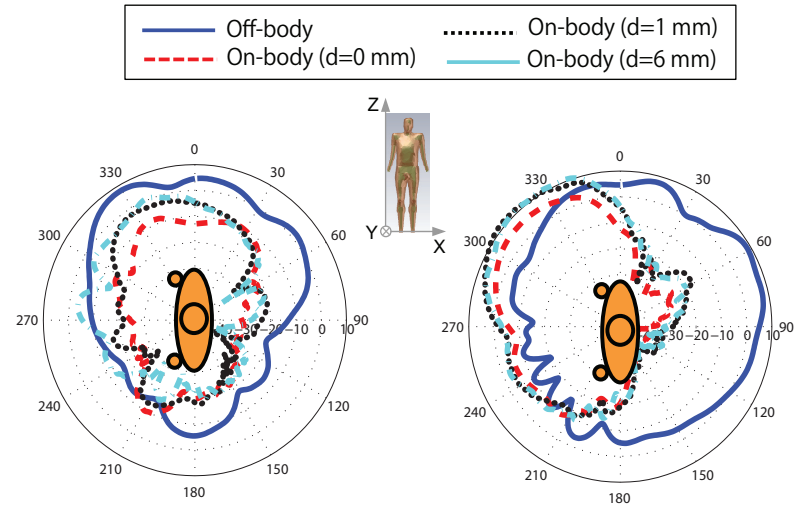

(i) XZ plane

(ii) YZ plane

(a) Simulation

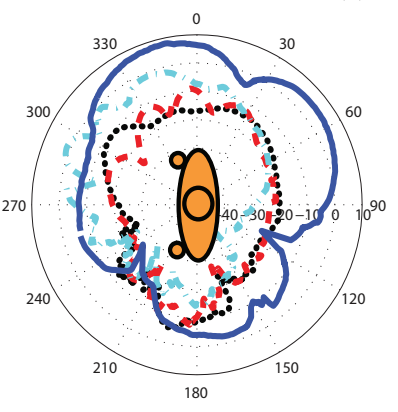

(i) XZ plane

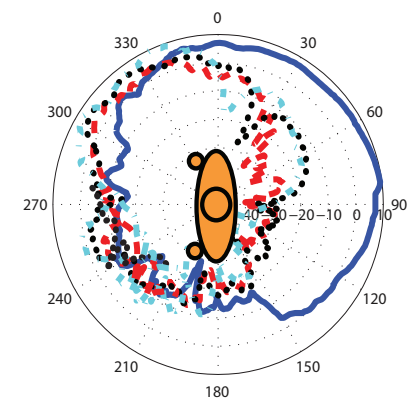

(ii) YZ plane (b) Measurement

Fig. 13. Comparison of simulated and measured radiation patterns of the proposed mm-Wave antenna in off-body and on-body scenarios at 60 GHz.

placements of the antenna on the body surface $(d=0 \mathrm{~mm}$ and $d=1 \mathrm{~mm}$ ). The placement at $d=0 \mathrm{~mm}$ loses $4.8 \mathrm{GHz}$ of the bandwidth while $d=1 \mathrm{~mm}$ placement has to bear a loss of $3.8 \mathrm{GHz}$ bandwidth due to change in the electrical properties of the substrate. These configurations however, succeed to retain a good impedance matching at the centre frequency of $60 \mathrm{GHz}$. The human body does not affect the antenna matching significantly when the body-antenna gap becomes $6 \mathrm{~mm}$ and it achieves a bandwidth of $9.3 \mathrm{GHz}$ 


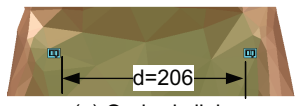

(a) On-body link

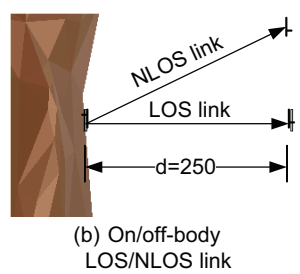

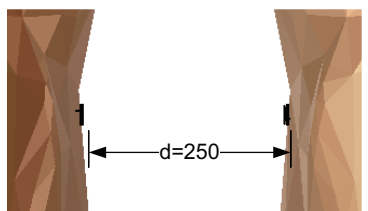

(c) Body-to-body link

Fig. 14. Experimental setup for body-centric channel characterisation for the proposed mm-Wave antenna (all units are in mm).

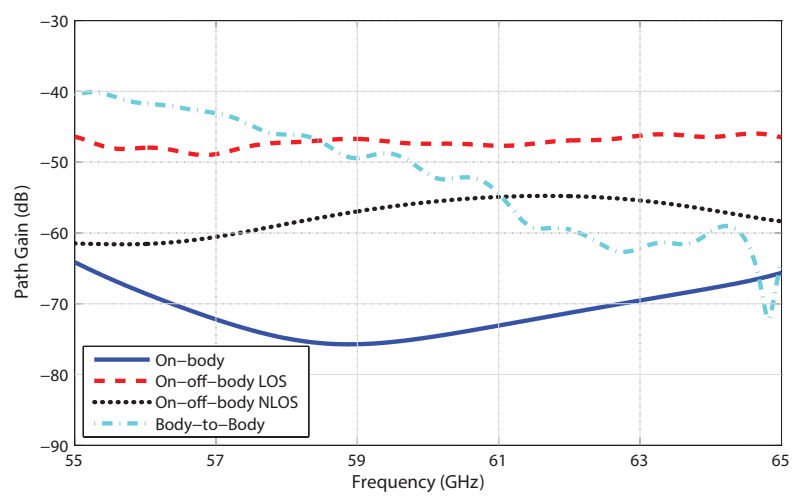

Fig. 15. Path gain response of the proposed antenna in different bodycentric channels.

which is comparable with the off-body configuration.

The antenna radiation patterns in on-body configurations follow a similar trend. The first two on-body configurations undergo larger deteriorations as compared to the $d=6$ $\mathrm{mm}$ configuration due to higher reflections from the body surface. In the three on-body scenarios, the human body backscatters the energy changing the induced current on the antenna structure. It results in lower back radiations and an increased maximum gain. The maximum gain values are observed to be $11.5 \mathrm{dBi}, 11.8 \mathrm{dBi}$ and $12.5 \mathrm{dBi}$ in simulation while $10.4 \mathrm{dBi}, 10.9 \mathrm{dBi}$ and $12.0 \mathrm{dBi}$ in measurement for $d=0 \mathrm{~mm}, d=1 \mathrm{~mm}$ and $d=6 \mathrm{~mm}$ placements, respectively. It shows a good agreement with a maximum difference of $1.1 \mathrm{~dB}$.

The antenna radiation efficiency in the presence of the human body also decreases due to absorptions in the lossy human body tissues. The simulated efficiency varies from $18 \%$ for $d=0 \mathrm{~mm}$ to $35 \%$ for $d=1 \mathrm{~mm}$ and $65 \%$ for $d=6 \mathrm{~mm}$. In measurements, efficiency is observed to be $10 \%$ for $d=0$ $\mathrm{mm}$ placement, $30 \%$ for $d=1 \mathrm{~mm}$ placement and reaches to $63 \%$ when $d=6 \mathrm{~mm}$. The maximum difference between the simulated and measured efficiency values is calculated to be $8 \%$.

These results show that in typical wearable configurations, where the antenna is located at $6 \mathrm{~mm}$ or more separation from the human body surface, the proposed antenna can work very well. It is therefore, suitable for body-worn applications where antenna is mounted on the circuit board or on top edge of the sensor/device.

\section{On-body Channel Characterisation}

The potential use of the proposed antenna in on/off-body communication necessitates an investigation of its response in on/off-body channel. The antenna performance in terms of path gain $\left(S_{21}\right)$ is therefore, evaluated considering various representative body-centric channels. The common scenarios of on-body channel between two body mounted antennas, on-off body channel where one antenna is bodyworn while the other is placed off-body at certain distance and body-to-body channel with two distant human subjects each wearing an antenna are investigated. For the on-off body channel, possibility of a line-of-sight (LOS) and nonline-of-sight (NLOS) link is also considered. The antenna is placed at a separation of $6 \mathrm{~mm}$ from the body surface in these studies. Fig. 14 depicts the experimental setup. The path length for the on-body link is $206 \mathrm{~mm}$ while it is kept at $250 \mathrm{~mm}$ for on-off body LOS, on-off body NLOS and bodyto-body links to satisfy the farfield radiation condition.

The results in Fig. 15 show that the path gain values lie between $-43 \mathrm{~dB}$ to $-73 \mathrm{~dB}$ for different body-centric channels when the antenna is operating at $60 \mathrm{GHz}$. The on-body channel is the weakest with a path gain of $-73 \mathrm{~dB}$ due to non-availability of a direct signal and high decay rate of the creeping wave signal. The LOS on-off body channel is the strongest with a path gain of $-43 \mathrm{~dB}$ due to strong direct signal. The body-to-body channel has a path gain of $-52 \mathrm{~dB}$ while the NLOS on-off body channel has achieved a path gain of $-55 \mathrm{~dB}$. It is evident from these results that the antenna establishes a good communication link at $60 \mathrm{GHz}$ guaranteeing continuous and robust working of the BCN systems.

\section{Comparison with Reported Wearable Millimeter-Wave Antennas}

The proposed antenna design is compared with related $60-\mathrm{GHz}$ antennas reported in open literature, [19]-[26], in terms of structure, size and radiation characteristics to show its effectiveness. Table I presents a summary of this comparative study.

It is evident that the proposed antenna exhibits a broader bandwidth than rest of the compared designs except presented in [26] that makes use of a complex geometry and requires specialised fabrication technology. Furthermore, the presented antenna employs a simple geometry with ease of fabrication through traditional low cost techniques and attains a size smaller than most of the reported designs except [24] and [25]. Most importantly, the proposed design 
TABLE I

COMPARISON BETWEEN THE PROPOSED ANTENNA AND STATE-OF-THE-ART MM-WAVE ANTENNAS.

\begin{tabular}{|c|c|c|c|c|c|c|c|}
\hline Ref. & Antenna structure & $\begin{array}{l}\text { Size } \\
(m m)\end{array}$ & $\begin{array}{l}-10 \mathrm{~dB} \text { BW } \\
(\mathrm{GHz})\end{array}$ & $\begin{array}{l}\text { Off-body } \\
\text { gain }(\mathrm{dBi})\end{array}$ & $\begin{array}{l}\text { On-body } \\
\text { gain }(\mathrm{dBi})\end{array}$ & $\begin{array}{c}\text { Off-body } \\
\text { efficiency(\%) }\end{array}$ & $\begin{array}{c}\text { On-body } \\
\text { efficiency }(\%)\end{array}$ \\
\hline [19] & $\begin{array}{l}\text { End-fire Yagi-Uda array } \\
\text { with } 18 \text { directors }\end{array}$ & $33 \times 15 \times 0.127$ & $55-60$ & 15 & $\mathrm{~N} / \mathrm{I}^{*}$ & $\mathrm{~N} / \mathrm{R}^{* *}$ & $\mathrm{~N} / \mathrm{I}^{*}$ \\
\hline [20] & $\begin{array}{l}\text { End-fire textile Yagi-Uda } \\
\text { array with } 10 \text { directors }\end{array}$ & $26 \times 8 \times 0.2$ & $57-64$ & 9.2 & 11.9 & 78 & 48 \\
\hline$[21]$ & $\begin{array}{l}\text { SIW-fed disc-like antenna } \\
\text { with dielectric loading }\end{array}$ & $49.7 \times 31 \times 3.1$ & 59.3-63.4 & 4.7 & 6.7 & 65 & 25 \\
\hline$[22]$ & $\begin{array}{l}\text { SIW horn with metallic } \\
\text { vias and plates }\end{array}$ & $24 \times 17 \times 0.79$ & $56.7-62.5$ & 6.6 & 4.4 & 92 & 62 \\
\hline [23] & $\begin{array}{l}\text { Microstrip-fed four-patch } \\
\text { array on } 3 \mathrm{~mm} \text { thick ground }\end{array}$ & $20 \times 8 \times 3.13$ & $59-65$ & 11.8 & 11.9 & 62 & 60 \\
\hline$[24]$ & $\begin{array}{c}\text { Quasi-Yagi array } \\
\text { loaded with three directors }\end{array}$ & $9.2 \times 10 \times 0.21$ & $57-66$ & 11.7 & $\mathrm{~N} / \mathrm{I}^{*}$ & $\mathrm{~N} / \mathrm{R}^{* *}$ & $\mathrm{~N} / \mathrm{I}^{*}$ \\
\hline [25] & $\begin{array}{l}\text { H-shaped microstrip } \\
\text { patch }\end{array}$ & $4.4 \times 5.5 \times 0.13$ & $59.2-64.1$ & 10.1 & $\mathrm{~N} / \mathrm{I}^{*}$ & $\mathrm{~N} / \mathrm{R}^{* *}$ & $\mathrm{~N} / \mathrm{I}^{*}$ \\
\hline$[26]$ & $\begin{array}{l}\text { Planar aperture on } \\
\text { LTCC having open cavity, } \\
\text { cross-strip, feeding network } \\
\text { and meshed ground }\end{array}$ & $12 \times 12 \times 1.13$ & $55.2-65.6$ & 12.1 & $\mathrm{~N} / \mathrm{I}^{*}$ & $\mathrm{~N} / \mathrm{R}^{* *}$ & $\mathrm{~N} / \mathrm{I}^{*}$ \\
\hline This work & $\begin{array}{l}\text { Microstrip antenna } \\
\text { with rectangular loop } \\
\text { and U-patches }\end{array}$ & $14 \times 10 \times 1.15$ & $55-64.8$ & 10.6 & 12.0 & 74 & 63 \\
\hline
\end{tabular}

${ }_{* *}^{*}$ The paper does not investigate human body effects on the antenna.

${ }^{* *}$ The authors have not reported this value.

works excellently in body-mounted configurations. Though, the gain and efficiency values in off-body (fee space) conditions are not the highest, they are greater than [21]-[23] and [25]. This comparison clearly shows the advantages of the proposed antenna for wearable applications at $60 \mathrm{GHz}$.

\section{Conclusion}

A novel patch-like antenna is presented for the BCN operation at millimetre-wave frequency band centred at 60 GHz. The proposed antenna has a simple structure and low profile realised through encompassing two U-shaped patches by a rectangular loop on a two-layer FPCB. A prototype of the antenna has been fabricated and tested for off-body (free space) and various on-body placements. The proposed antenna has achieved a bandwidth of 9.8 $\mathrm{GHz}$ covering frequencies from $55 \mathrm{GHz}$ to $64.8 \mathrm{GHz}$, a peak gain of $10.6 \mathrm{dBi}$ with good radiation coverage and radiation efficiency of $74 \%$ in off-body scenario. A good agreement between the simulated and measured results has been observed.

Though, the antenna has experienced detuning, pattern degradation and drop in the efficiency in the on-body placements with antenna-body gap of $0 \mathrm{~mm}$ and $1 \mathrm{~mm}$, it performed excellently when positioned at a distance of $6 \mathrm{~mm}$ from the human body surface replicating typical body-mounted scenarios. The antenna has exhibited a gain of $12.1 \mathrm{dBi}$ and efficiency of $63 \%$ for this on-body placement. The antenna has also successfully established a good wireless link for on-off body LOS, on-off body NLOS and body-to-body communication scenarios with a path gain of $-43 \mathrm{~dB},-55 \mathrm{~dB}$ and $-52 \mathrm{~dB}$, respectively. Consequently, this very low profile antenna is a well-suited candidate for bodycentric wireless devices and IoT applications operating at millimetre-wave frequencies .

\section{ACKNOWLEDGEMENT}

The authors would like to thank Mr. Dongjian Cao for his help in the measurements. The work was supported in part by the National Natural Science Foundation of China (Grant No. 61671349), Fundamental Research Funds for the Central Universities, Project Funded by China Postdoctoral Science Foundation and Postdoctoral Research Projects Funded in Shaanxi Province.

\section{REFERENCES}

[1] Q. H. Abbasi, M. Ur-Rehman, K. Qaraqe, and A. Alomainy, "Advances in body-centric wireless communication: Applications and state-ofthe-art," the IET, (UK), 2016.

[2] P. S. Hall and Y. Hao, "Antennas and propagation for body-centric wireless networks (2nd Edition)," Artech House, 2012.

[3] X. Chen, C. G. Parini, B. Collins, Y. Yao, and M. U. Rehman, "Antennas for global navigation satellite systems," John Wiley and Sons, Inc., (UK), 2012.

[4] Z. N. Chen, “Antennas for portable devices," John Wiley and Sons, Inc., $(U K), 2007$.

[5] "Wearable device market forecasts," Tactica, March 2015.

[6] L. Sorensen and K. Skouby, "User scenarios 2020 a worldwide wireless future," WWRF, July 2009, URL: http://www.wwrf.ch/files/publications. 
[7] Y. Niu, Y. Li, D. Jin, L. Su, and A. V. Vasilakos, "A survey of millimeter wave communications (mmWave) for 5G: opportunities and challenges," Springer Wireless Networks, vol. 21, no. 8, pp. 2657-2676, 2015.

[8] M. Ur Rehman, Y. Gao, Z. Wang, J. Zhang, Y. Alfadhl, X. Chen, C. Parini, Z. Ying, and T. Bolin, "Investigation of on-body bluetooth transmission," IET Microwaves, Antennas and Propagation, vol. 4, no. 7 , pp. 871-880, July 2010.

[9] G. A. Conway and W. G. Scanlon, "Antennas for over-body-surface communication at $2.45 \mathrm{GHz}$," IEEE Transactions on Antennas and Propagation, vol. 57, no. 4, pp. 844-855, April 2009.

[10] Q. Abbasi, A. Alomainy, and Y. Hao, "Characterization of MB-OFDMbased ultrawideband systems for body-centric wireless communications," IEEE Antennas and Wireless Propagation Letters, vol. 10, pp. 1401-1404, 2011.

[11] W. T. Shay, S. C. Jan, and J. H. Tarng, "A reduced-size wide slot antenna for enhancing along-body radio propagation in UWB on-body communications," IEEE Transactions on Antennas and Propagation, vol. 62, no. 3, pp. 1194-1203, 2014.

[12] Z. Wang, L. Z. Lee, D. Psychoudakis, and J. L. Volakis, "Embroidered multiband body-worn antenna for GSM/PCS/WLAN communications," IEEE Transactions on Antennas and Propagation, vol. 62, no. 6, pp. 3321-3329, 2014.

[13] M. Ur-Rehman, Q. Abbasi, M. Akram, and C. Parini, "Design of bandnotched ultra wideband antenna for indoor and wearable wireless communications," IET Microwaves, Antennas Propagation, vol. 9, no. 3, pp. 243-251, 2015.

[14] T. W. Koo, Y. J. Hong, G. k. Park, K. Shin, and J. G. Yook, "Extremely low-profile antenna for attachable bio-sensors," IEEE Transactions on Antennas and Propagation, vol. 63, no. 4, pp. 1537-1545, 2015.

[15] S. Yan, P. J. Soh, and G. A. E. Vandenbosch, "Dual-band textile MIMO antenna based on substrate-integrated waveguide (SIW) technology," IEEE Transactions on Antennas and Propagation, vol. 63, no. 11, pp. 4640-4647, 2015.

[16] C. C. Y. Poon, B. P. L. Lo, M. R. Yuce, A. Alomainy, and Y. Hao, "Body sensor networks: In the era of big data and beyond," IEEE Reviews in Biomedical Engineering, vol. 8, pp. 4-16, 2015.

[17] A. Pellegrini, A. Brizzi, L. Zhang, K. Ali, Y. Hao, X. Wu, C. C. Constantinou, Y. Nechayev, P. S. Hall, N. Chahat, M. Zhadobov, and R. Sauleau, "Antennas and propagation for body-centric wireless communications at millimeter-wave frequencies: A review [wireless corner]," IEEE Antennas and Propagation Magazine, vol. 55, no. 4, pp. 262-287, 2013.

[18] X. Y. Wu and P. S. Hall, "Substrate integrated waveguide Yagi-Uda antenna,” Electronics Letters, vol. 46, no. 23, pp. 1541-1542, November 2010.

[19] X. Y. Wu, L. Akhoondzadeh-Asl, and P. S. Hall, "Printed Yagi-Uda array for on-body communication channels at $60 \mathrm{GHz}$," Microwave and Optical Technology Letters, vol. 53, no. 12, pp. 2728-2730, 2011.

[20] N. Chahat, M. Zhadobov, L. L. Coq, and R. Sauleau, "Wearable endfire textile antenna for on-body communications at $60 \mathrm{GHz}$," IEEE Antennas and Wireless Propagation Letters, vol. 11, pp. 799-802, 2012.

[21] J. Puskely, M. Pokorny, J. Lacik, and Z. Raida, "Wearable disc-like antenna for body-centric communications at $61 \mathrm{GHz}$," IEEE Antennas and Wireless Propagation Letters, vol. 14, pp. 1490-1493, 2015.

[22] S. Razafimahatratra, J. Sarrazin, A. Benlarbi-Delai, T. Mavridis, L. Petrillo, P. D. Doncker, C. Leduc, M. Zhadobov, and R. Sauleau, "On-body propagation characterization with an H-plane substrate integrated waveguide (SIW) horn antenna at $60 \mathrm{GHz}$," European Microwave Conference (EuMC), pp. 211-214, Sept 2015.

[23] N. Chahat, M. Zhadobov, L. L. Coq, S. I. Alekseev, and R. Sauleau, "Characterization of the interactions between a $60-\mathrm{GHz}$ antenna and the human body in an off-body scenario," IEEE Transactions on Antennas and Propagation, vol. 60, no. 12, pp. 5958-5965, Dec 2012.

[24] L. Lu, K. Ma, F. Meng, and K. S. Yeo, "Design of a 60-GHz quasiyagi antenna with novel ladder-like directors for gain and bandwidth enhancements," IEEE Antennas and Wireless Propagation Letters, vol. 15, pp. 682-685, 2016.

[25] M. S. Rabbani and H. Ghafouri-Shiraz, "Improvement of microstrip patch antenna gain and bandwidth at $60 \mathrm{GHz}$ and $\mathrm{X}$ bands for wireless applications," IET Microwaves, Antennas Propagation, vol. 10, no. 11, pp. 1167-1173, 2016.

[26] S. Liao and Q. Xue, "Dual polarized planar aperture antenna on ltcc for $60-\mathrm{GHz}$ antenna-in-package applications," IEEE Transactions on Antennas and Propagation, vol. 65, no. 1, pp. 63-70, Jan 2017.

[27] CST Microwave Studio ${ }^{\circledR} 2016$ User Manual.
[28] S. Gabriel, R. W. Lau, and C. Gabriel, "The dielectric properties of biological tissues: II. measurements in the frequency range $10 \mathrm{~Hz}$ to $20 \mathrm{GHz}, "$ Physics in Medicine and Biology, vol. 41, no. 11, pp. 22512269, 1996.

[29] "Dielectric properties," ITIS website, http://http://wwwitis.ethz.ch/virtualpopulation/tissue-properties/database/dielectric-properties).

[30] O. G. Martinsen, S. Grimmes, and H. P. Schwan, "Encyclopedia of surface and collied science," Marcel Dekker, 2002.

[31] N. Chahat, M. Zhadobov, and R. Sauleau, "Broadband tissueequivalent phantom for BAN applications at millimeter waves," IEEE Transactions on Microwave Theory and Techniques, vol. 60, no. 7, pp. 2259-2266, 2012.

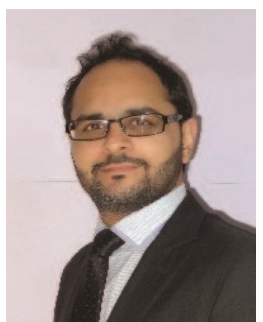

Masood Ur Rehman (SM'16) received the B.Sc. degree in electronics and telecommunication engineering from University of Engineering and Technology, Lahore, Pakistan in 2004 and the M.Sc. and $\mathrm{Ph} . \mathrm{D}$. degrees in electronic engineering from Queen Mary University of London, London, UK, in 2006 and 2010, respectively. He worked at Queen Mary University of London as a Postdoctoral Research Assistant till 2012 before joining the Centre for Wireless Research at University of Bedfordshire, University Square, Luton, UK, as a

Lecturer.

His research interests include compact antenna design, radiowave propagation and channel characterization, satellite navigation system antennas in cluttered environment, electromagnetic wave interaction with human body, body-centric wireless networks and sensors, remote health care technology, mmWave and nano communications for body-centric networks and $\mathrm{D} 2 \mathrm{D} / \mathrm{H} 2 \mathrm{H}$ communications. He has worked on a number of projects supported by industrial partners and research councils. He has contributed to a patent and authored/co-authored 4 books, 7 book chapters and more than 70 technical articles in leading journals and peer reviewed conferences.

Dr. Ur Rehman is a Fellow of the Higher Education Academy (UK), a member of the IET and part of the technical program committees and organizing committees of several international conferences, workshops and special sessions. He is acting as an Associate Editor of the IEEE Access and Lead Guest Editor of numerous special issues of renowned journals. $\mathrm{He}$ also serves as a reviewer for book publishers, IEEE conferences and leading journals.

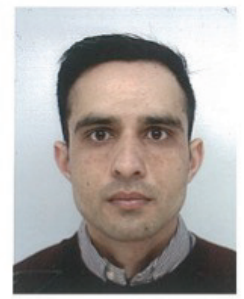

Nabeel Ahmed Malik received the B.Sc degree in electrical and electronic engineering from Mirpur University of Science and Technology, Mirpur AJK, Pakistan in 2012. He received the degree in MSc electronic engineering from University of Bedfordshire, Luton, UK in 2015. He is currently pursuing his $\mathrm{PhD}$ in wireless communications in the Centre for Wireless Research at University of Bedfordshire, Luton UK. His research interests include antenna design, radiowave propagation and mmWave communications for body-centric

networks.

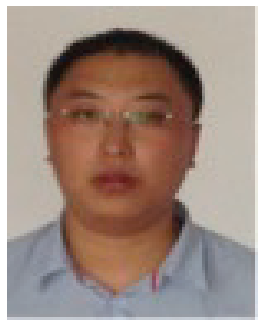

Xiaodong Yang (M'12) has published over 30 peerreviewed journal papers, including IEEE Transactions and Letters. His current research interests include body area networks, biomedical communications, antennas \& propagation, physical layer security, and wireless power transfer. Dr. Yang received the Young Scientist Award from the International Union of Radio Science in 2014. He is an active reviewer for IEEE Transactions and Letters. 


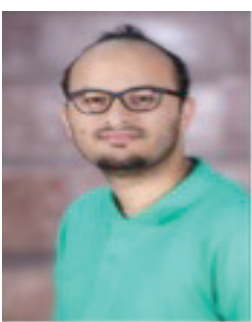

Qammer Hussain Abbasi (SM'16) received his BSc and MSc degree in electronics and telecommunication engineering from University of Engineering and Technology, Lahore, Pakistan (with distinction). He received his Ph.D. degree in Electronic and Electrical engineering from Queen Mary University of London, UK, in January 2012. From February 2012 to June 2012, he was Post-Doctoral Research Assistant in Antenna and Electromagnetics group at Queen Mary University of London, UK. From 2012 to 2013, he was international young scientist under National Science Foundation China (NSFC), and Assistant Professor in University of Engineering and Technology, KSK, Lahore. From August, 2013 to April 2017 he was with the Centre for Remote Healthcare Technology and Wireless Research Group, Department of Electrical and Computer Engineering, Texas A \& M University (TAMUQ) initially as an Assistant Research Scientist and later was promoted to an Associate Research Scientist and Visiting lecture where he was leading multiple Qatar national research foundation grants (worth $\$ 3$ million). Currently, Dr. Abbasi is a Lecturer (Assistant Professor) in University of Glasgow in the School of Engineering in addition to Visiting Research Fellow with Queen Mary, University of London and Visiting Associate Research Scientist with Texas A \& M University. He has been mentoring several undergraduate, graduate students and postdocs. Dr. Abbasi has contributed to a patent, more than 100 leading international technical journal and peer reviewed conference papers and 5 books and received several recognitions for his research. His research interests include compact antenna design, RF design and radio propagation, nano communication, Biomedical applications of Terahertz communication, Antenna interaction with human body, Implants, body centric wireless communication issues, wireless body sensor networks, non-invasive health care solutions, cognitive and cooperative network and multiple-input-multiple-output systems. He is an Associate Editor for IEEE Access journal and acted as a guest editor for numerous special issues in top notch journals. Dr. Abbasi has been a member of the technical program committees of several IEEE flagship conferences and technical reviewer for several IEEE and top notch journals. He contributed in organizing several IEEE conferences, workshop and special sessions in addition to European school of antenna course. 